$12^{\text {th }}$ International Conference on Structural Analysis of Historical Constructions

\title{
COMPARISON ON METHODOLOGIES AND INTERVENTIONS FOR TWO MASONRY CHURCHES AFFECTED AFTER THE 2017 EARTHQUAKE IN MEXICO
}

\author{
M. ESPONDA ${ }^{1 *}$, AND J. COOKE ${ }^{2}$ \\ ${ }^{1}$ Associate Professor and Coordinator of the Conservation Program \\ at the Azrieli School of Architecture \\ Carleton University, Ottawa, ON, Canada \\ e-mail: mariana_esponda@carleton.ca \\ ${ }^{2}$ Senior Structural/Conservation Engineer at John G. Cooke \& Associates Ltd. and Adjunct Professor \\ at the Azrieli School of Architecture \\ Carleton University, Ottawa, ON, Canada \\ email: jcooke@jgcooke.com
}

Keywords: Historical Structure with Unreinforced Masonry, Earthquakes in Mexico, Traditional vs Contemporary Intervention, Material Compatibility, Vapour Transmission.

Abstract. The current state of two 16th century masonry churches were studied after being damaged during the 2017 earthquake in Mexico. The two complexes being analyzed are part of the World Heritage Site "Ruta de los Conventos": the Convento de San Guillermo Totolapan, in the state of Morelos south-east of Mexico City, and the Huaquechula Monastery, in the state of Puebla south of Mexico City. These buildings are representative of the architectural model adopted by the first missionaries who evangelized the indigenous populations in the 16th century. The churches were constructed circa 1535 and 1548, respectively. The history and cultural significance for each project is researched in coordination with the stakeholders, along with the contrasting structural systems and any known previous interventions, historic and contemporary.

The damage inflicted to the two churches due to the most recent earthquake (2017) is critically analyzed, specifically focusing on inherent defects of the existing materials, the variation in construction methodologies and the impact of contemporary interventions such as the use of reinforced concrete and structural steel following previous earthquakes. Potential repair methodologies are discussed in order to mitigate future damage to the structures. Discussions include the importance of using compatible materials along with appropriate repair procedures and the need for ongoing maintenance of these important heritage structures. 


\section{INTRODUCTION}

The deterioration of heritage sites resulting from natural disasters is a loss to humanity's culture. However, most existing studies on earthquakes focus on the effects on building materials from a technical standpoint. There is a need for further studies which balance the technical requirements with the significance of built heritage, focusing on risk management and the implementation of interventions which embrace appropriate technologies. There is also a general lack of understanding among the Architectural/Engineering community as to how Unreinforced Masonry (URM) structures function, how to preserve them and, where necessary, how to rehabilitate these structures. There is a misunderstanding that URM reacts poorly to seismic forces, producing extensive structural damage and loss of life. Yet, in many countries, there is evidence of masonry structures that have endured for centuries in areas of high seismic activity, simply by performing regular maintenance on the masonry with compatible materials.

This prevents long term neglect and deterioration, which is the ultimate cause of structural failure. In the authors experience, it is the inability to manage moisture in masonry and resulting moisture damage that the single greatest cause of structural damage to masonry. Using contemporary materials such as Portland cement blocks vapour transmission and results in a significant proportion of the damage seen to heritage sites.

Being one of the world's most earthquake-prone countries, Mexico has been a victim of many seismic events of moderate to high intensity. Intersecting tectonic plates create subduction zones that generate high-intensity earthquakes, which can be very destructive. In the 20 th century al area, with most of three of these earth

More recently, September 8 just
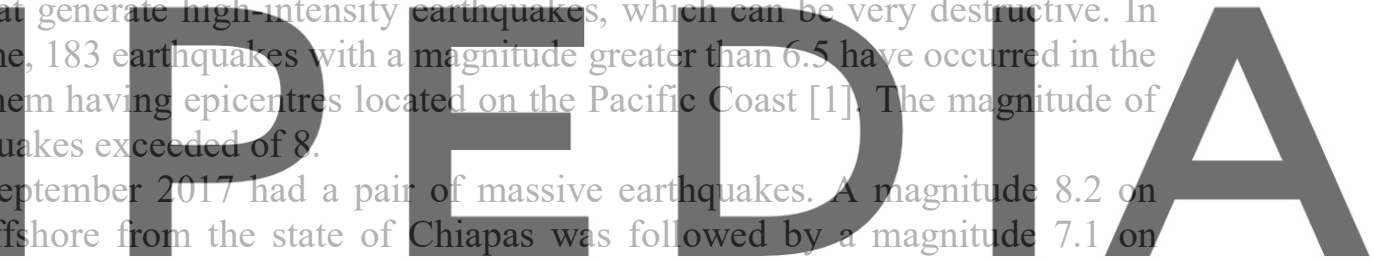

September 19, this time much closer to Mexico City, and caused heavy destruction in 11 states

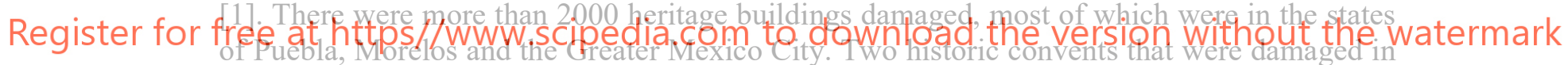
2017 and are considered the most endangered were visited and analysed by the authors several times during 2019 (January, May and December) and are the current study: Convento de San Guillermo Totolapan, in the state of Morelos south of Mexico City, built circa 1535, and the Huaquechula Monastery, in the state of Puebla south-east of Mexico City, built circa 1548.

The damage from the 2017 earthquake is in the process of being repaired for both of these sites. It is important to assess the damage to understand how the structure behaved in the recent earthquake, and use this information to perform appropriate repairs in order to mitigate future destruction. Much of the damage which occurred during these most recent earthquakes was related to the existing conditions, contemporary changes made to the structures, and lack of maintenance. The term "appropriate repairs" refers to using compatible materials, understanding the evolution and changes through many centuries, designing interventions that work with the existing structural system, and focussing on the need for ongoing maintenance. These recent events prove that it is critical to evaluate the current state of built heritage in order to be better prepared for future earthquake disasters. 


\section{HISTORY}

The early monasteries were not established in the style of ancient European monasteries, as places to live in isolation or divine contemplation. Instead, these convents functioned as dynamic cultural centres for religious dissemination, with schools where they transmitted the cultural elements brought from Europe, including basic beliefs of native cultures. The monasteries were founded with only a few mendicant friars who arrived in Mexico between 1523 and 1533 . They were the alchemists, blending the two cultures into a new identity.

The main characteristic of these monuments is the "monastic fortress"; the impressive sobriety typical of the first attempts in which the friars had to explain to the indigenous builders the necessary criteria for these buildings [2]. The simplicity in the massing, crenellation and massive walls, small high windows and square buttresses, the integration of indigenous reliefs, and the reuse of stones from other ceremony sites are some of the main attributes.

In 1994, 14 monasteries called "Ruta de los Conventos", on the slopes of Popocatepet1, were designated a UNESCO World Heritage Site [3]. The Totolapan monastery is included in the designation. The Huaquechula monastery, despite having the same characteristics as the others, was not inscribed. These buildings are representative of the architectural model adopted by the first missionaries who evangelized the indigenous populations in the 16th century. The monasteries were founded in areas of dense indigenous settlement, with the object of providing focal points for urban settlements, a role which has survived to the present day. The fusion of
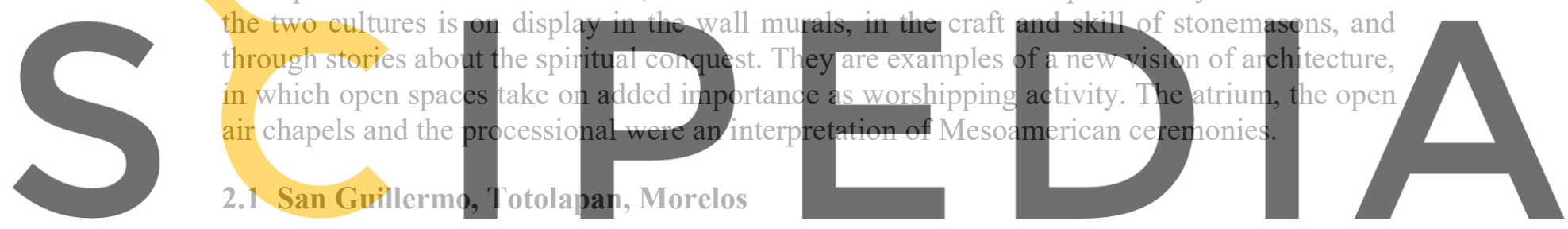

The Convent of San Guillermo is a very good example of "primitive convent architecture".

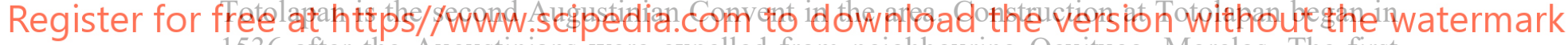
1536 after the Augustinians were expelled from neighbouring Ocuituco, Morelos. The first stage was completed in 1545 under the direction of the head master Jorge de Avila [4]. The complex of Totolapan is more modest in dimensions and decoration than the other convents in Morelos that were built later for the same religious order - Tlayacapan and Yecapixtla.

Totolapan contains certain basic elements common to this new type of monastery: a collection of buildings surrounding a great rectangular atrium, well demarcated by an atrium wall. In the atrium's internal perimeters there are two Processional Chapels. The church is located to the south of the monastic buildings, positioned around a small courtyard patio. There is also the open chapel in front of the atrium, highlighting the importance of open spaces to evangelize the indigenous people.

The church, with a single nave, is simple in plan and has less imposing proportions than other monasteries. The roof of the nave is a longitudinal barrel vault with lunette windows, without ribs, and is subdivided into four bays reinforced by transverse arches. The exterior is delineated by masonry buttresses at the arches. The nave is 28 meters long and 11 meters wide. The apse is covered by a large pendentive dome, much thinner than the walls with the thickness decreasing linearly up from the walls. It is possible, as Roberto Meli stated, that the roof was likely originally a wooden gable roof with ceramic tiles, and the barrel vault could be a 17 th 
century modification [4]. In the adjacent buildings, the roofs consist of smaller barrel vaults. The mortar to stone ratio is much greater in the vaults than in the walls.

The Totolapan convent was constructed of a mix of adobe mortar, volcanic stone and pebble stone. The thickness of the walls varies up to 2 meters. The quality of the masonry walls is poorer than the Huaquechula monastery. Much smaller round river stone was used, with less evidence of the larger angular masonry, and an overall lack of keying stones. Since the Totolapan was completed earlier, this suggests that the quality of these complexes improved with experience.

The known interventions are listed below, but the age of the structure and high seismicity of the region guarantees that work had been done previously on both monasteries (due to previous seismic events, wars, alterations or changes of use). In 1949, the first recorded intervention, the main wooden altar was replaced with concrete due to insect damage. In 1964, the roof was refinished with a waterproof coating using traditional, pre-hispanic methods. The coating consisted of lime, sand, laundry detergent, water and alum to create a waterproofing substance which they sampled on certain mural paintings on the walls.

The convent was damaged by a 6.7 magnitude earthquake on August 17, 1969. The barrel yaults experienced significant cracking, and were repaired using the galette technique. This technique uses small pieces of tezontle (a local volcanic stone that is extremely porous) in a mortar mix consisting of lime, Portland cement, and sand in a 1:1:3 ratio. They used this material to replace all of the existing vault material that was deemed to be in poor condition.

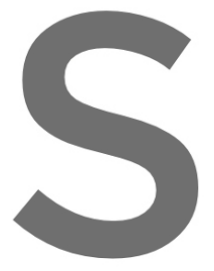
The vaults were re-sung church was repaire added and was subseq

A condition asse poor condition due to mortar on the exterior of the
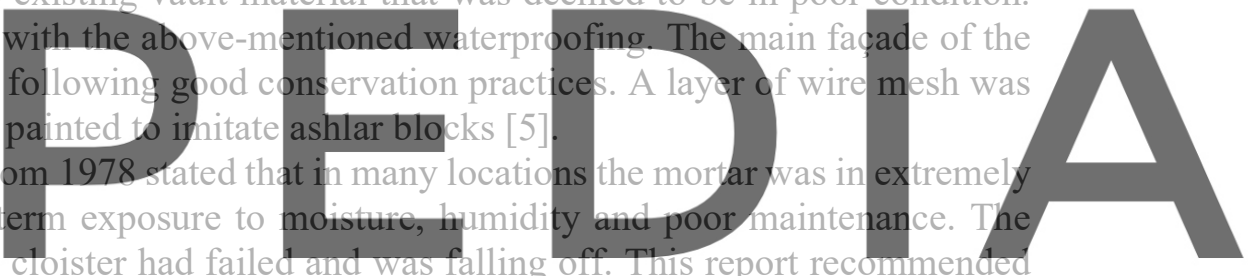

the intervention of reinforcing the barrel vault by injecting cement into the slab.

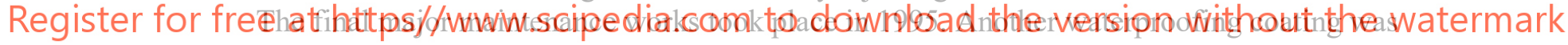
added to the roof, some of the mortar was repointed, the main facade was painted, and some of the walls and buttresses were reconsolidated. The existing cracks on the east/west walls of the convent were repaired with injected cement grout [5].

\subsection{The Huaquechula Monastery "Ex-Convento de San Martin"}

The Huaquechula monastery was constructed between 1531 and 1569 by the Franciscan order under the direction of Juan de Alameda as the head Master Builder. It was constructed with unreinforced massive stone masonry of a higher quality than Totolapan. The use ashlar stones larger and more angular in shape demonstrates a knowledge of stereotomy [6]. The facade is Plateresque with a richly adorned main portal in sandstone and decorated with two Franciscan coat of arms and two angels. The church is a longitudinal nave with four stone ribbed vaults consisting of volcanic stone, pebble stone and adobe mortar. These stone ribs are carved ashlar finished stones constructed as intersecting arches. The church measures 48 x 14 meters and is braced by massive buttresses on the north side and a two storey convent structure with integrated buttresses on the south side. The main altarpiece from 17th century is over ten meters high and five meters wide and has paintings by Cristobal de Villalpando. The former cloister 
area was rehabilitated, years ago, as a local museum. The walls still contain remnants of the monastery's rich mural work, and the rooms contain archaeological pieces and copies of various codices. Following the damages from the 2017 earthquake the museum was closed.

The Huaquechula Monastery was previously damaged during the major earthquake of 1999. At that time, the upper portion of the bell tower was reinforced with concrete and steel angles, which were anchored into the stone pillars with rebar. Based on evidence noted on site, it is assumed that the repair works at that time did not include repointing of the masonry piers. Also, the roof of the two storey convent, which consisted of heavy timber structure, with plank decking, was replaced by a concrete roof slab.

From 2012 until 2016 some conservation works continued in Huaquechula. The Conservators performing some patching in the walls and ribbed vault, with cementitious materials. Some maintenance work in the cloister was also in progress.

\section{CONSTRUCTION TECHNIQUES}

The construction of buildings by using the local subsoil is one of the oldest construction techniques [7]. In North America, the most prominent use of earthen construction was by the Indigenous People of Mexico and the southern United States. Before the arrival of Europeans to the area, pyramids and vernacular buildings were typically constructed of adobe which had proven over time to be a durable construction assembly.
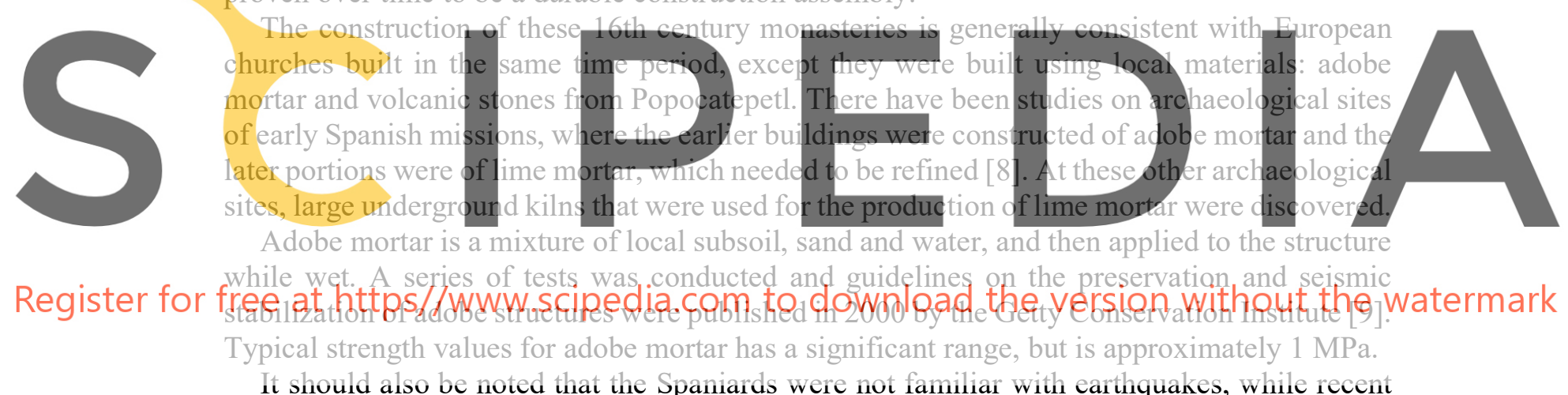

It should also be noted that the Spaniards were not familiar with earthquakes, while recent studies have shown that the Indigenous people knew how to construct adobe buildings to resist seismic forces. A study in the same region showed that well-maintained traditional adobe buildings performed significantly better than those with modern interventions such as concrete roofs, large windows, or additions [10]. These monasteries were built with indigenous labour that provided wisdom in the preparation and selection of raw materials.

However, the monasteries were constructed largely in the European style. The tall, vaulted masonry roofs with thick, buttressed walls were imported architectural features that had been refined by trial and error overseas. Historic designers and Master Builders had a knowledge and understanding of mass masonry buildings, passed down over centuries, that does not have a place in modern engineering. Prior to any rehabilitation project it is important for the engineer to understand the principles behind mass masonry. Arches or vaults, for example, are abundant and simple in form yet not immediately logical to analyse according to modern engineering principles [11]. There are many resources available which describe the principles of masonry which is outside the scope of this current report. 


\section{BUILDING CONDITION}

\subsection{The Convent San Guillermo Totolapan}

The Totolapan monastery suffered significant damage during the 2017 earthquake. The barrel vaults of the church experienced significant cracking and fracturing. Part of the bell tower collapsed. The pendentive dome completely failed during the earthquake, shearing where the vault is the thinnest. The damage to the cloister includes significant fracturing of the barrel vault roofs, cracking of the walls and failure of many of the buttresses in the courtyard. At the east and west side of the courtyard, the barrel vault roofs had collapsed.
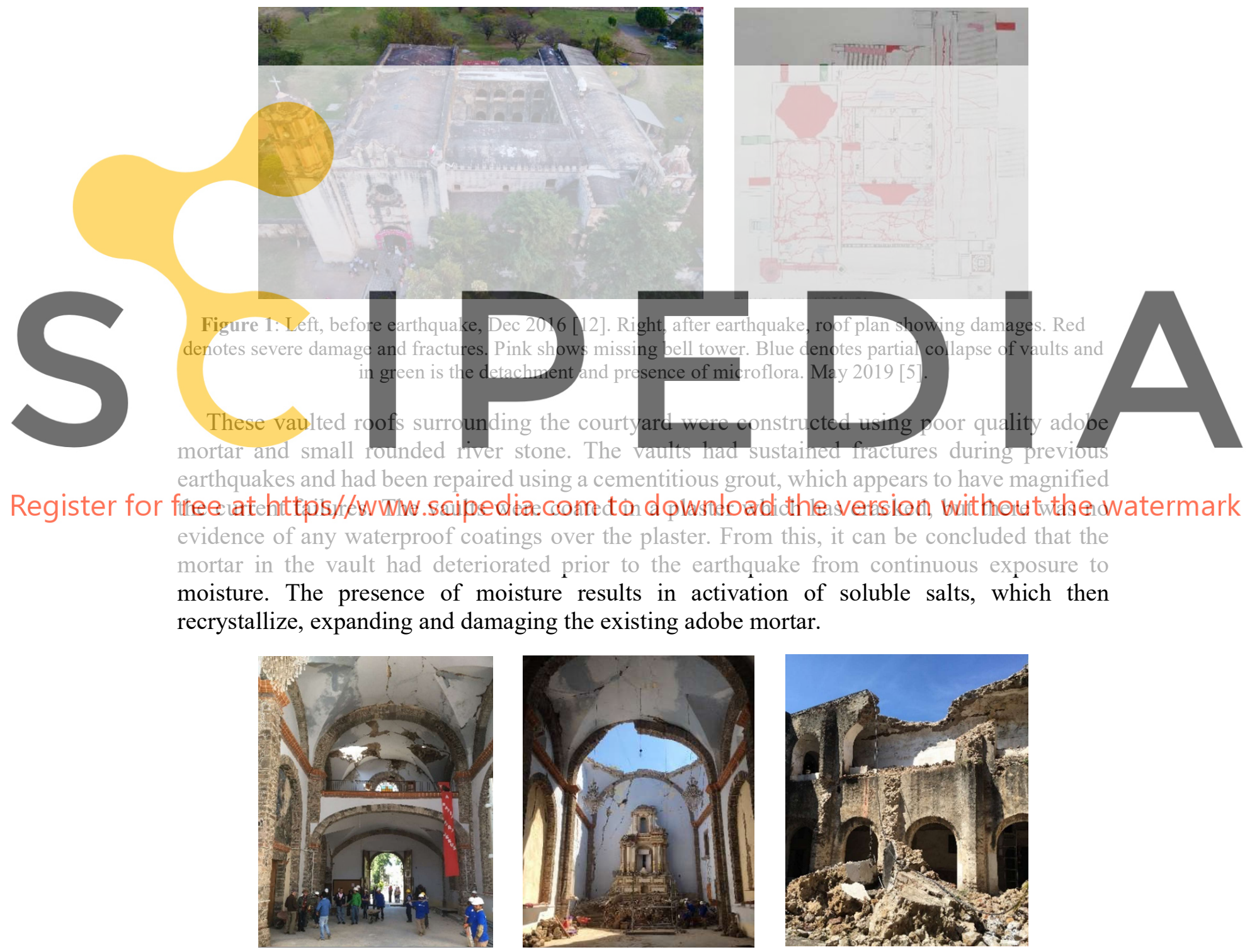

Figure 2: Photographed damage 4 weeks after the earthquake, Oct. 2017. Left: Fractures and partial collapse of nave vault. Center: Complete failure of the apse dome. Right: Collapse of vault and buttresses of the cloister. 
The walls of the nave had also experienced large fractures, and many of the large buttresses were damaged, some completely collapsed and others fractured full height at the face of the walls. Some of the buttresses at the cloister failed due to bending perpendicular to the wall. There was a general lack of large tie stones to hold the masonry together. The major fractures to the walls were noted mainly where they intersected the exterior walls, or through wall openings. Several infill walls in original arches had also displaced.

The large bell tower, the stone arch above the entrance that supports the open bells, and some of the crenellations around the roof, fell outwards. The bell tower was constructed such that it was only attached to the main structure at one corner. Once it separated from the nave, it became a tall slender structure, with a different mode of vibration to the main structure.

At the other corner of the monastery there is a smaller masonry bell tower which was also damaged. It appears that the rocking of the tower resulted in hinges forming at the base of the four corner pillars, and in the apex of the arches between the pillars. It was observed that at each of the hinge locations, where the plaster had spalled, dislodged and debonded loose rubble masonry was observed. The staining indicates mould and long-term moisture saturation.

Work is proceeding on smaller areas before the more extensive interventions. Most fractured walls of the church are being consolidated, by drilling ports and inserting small copper pipes in the walls. A mix of lime, sand and pozolime grout is injected. The collapsed buttresses are also being rebuilt, using metallic ties to anchor to the walls.
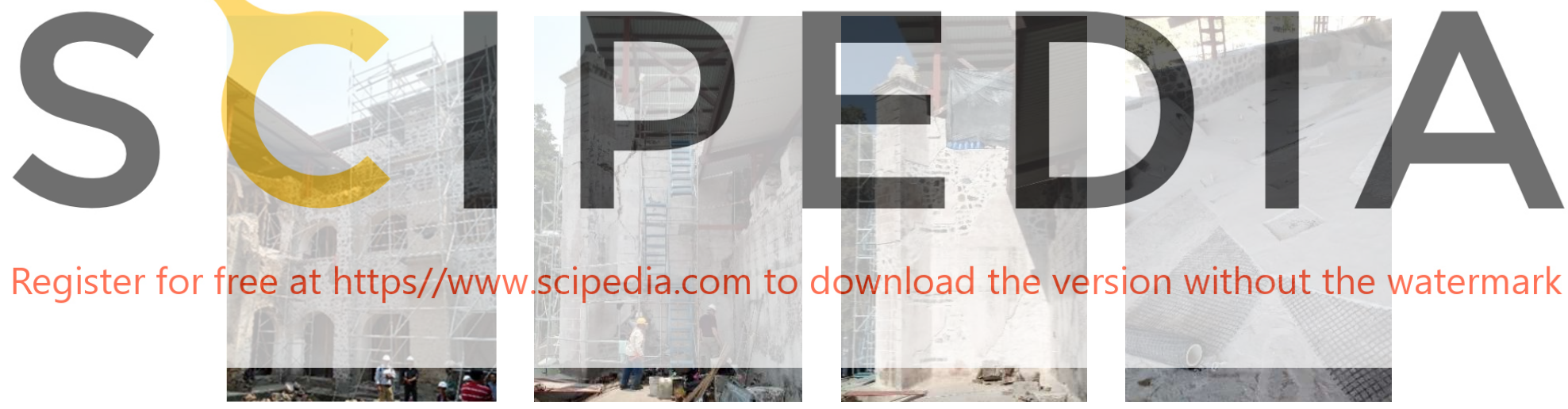

Figure 3: Left: Reconstruction and consolidation of walls and buttresses in the courtyard, Dec 2019. Two central images: Bell tower with damages, May 2019, and after repair by integrating horizontal large volcanic stones, Dec 2019. Right: Rehabilition of the roof vault by adding carbon fibres in a cross pattern, Dec 2019.

The large fractures in the apse walls are being repaired by first dismantling the masonry on each side of the fracture and removing all debonded material. The wall then is rebuilt across the crack, with compatible mortars and large volcanic stones -basalto- of high density and strength. This is an excellent solution as compatible materials are used to reinforce the masonry at known weak points. Provided that the mortars are compatible with the original adobe mortars, with similar strength and porosity, this will permit vapour transmission from the original to the new masonry and allow the assembly to function as originally intended. This construction also bonds well with the existing masonry, so that they can function as a single unit in future earthquakes. It is critical, as part of the rebuilding, that all dust is removed at the interface between the old and new mortar, otherwise the bond between these two materials will not occur. 
They are also introducing tensile strength to the top of the nave barrel vaults by applying carbon fibre to better resist the formation of hinges and therefore seismic forces. The methodology applied in the barrel vault followed the cleaning of the whole area, drilling ports and injecting traditional mortar into the fractures, and applying the carbon fibre in a cross " $\mathrm{X}$ " pattern which is anchored to the barrel vault slab. This is a new methodology that has just been initiated in rehabilitation projects in L'Aquila, Italy after the 2009 earthquake. It will be important to monitor this new intervention for its compatibility with the 500-year-old structure.

During the site visit in May of 2019, a sample was taken of the Totolapan buff mortar. Ken Trischuk from the National Research Council of Canada performed tests for composition and strength. The strength of the single mortar sample was $8.29 \mathrm{MPa}$, and composed predominantly of calcium, carbon and oxygen; the typical signature for lime mortar. However, the main point highlighted by this sample is that more need to be taken from various locations around the complex to identify the existing conditions and mortar composition.

\subsection{The Huaquechula Monastery}

The Huaquechula Monastery experienced significant damage during the 2017 earthquake. The upper portion of the bell tower collapsed and fell through the first ribbed vault roof of the nave. The main facade has a large central entrance door under an ornate rose window. These openings substantially weakened the wall, resulting in a large vertical shear fracture. The
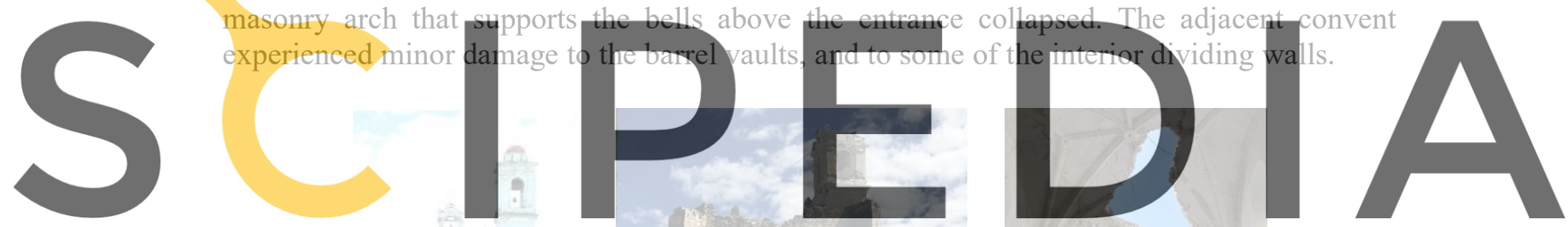

Register for free at htțps//www.scipedia.com to download

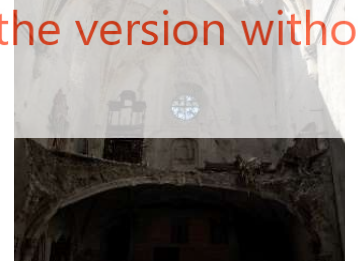

Figure 4: Left: Before the earthquake, May 2017 [13]. Center: After the earthquake, Oct 2017. Right: Damage sustained by the ribbed vault caused by the collapse of the top part of the bell tower, Oct 2017.

The bell tower failed at mid-height, collapsing into the nave during the earthquake. It is important to highlight the entire section which had been reinforced with concrete and steel in 1999 had collapsed. The steel angles were still on site in May 2019, and except for minor bending, the entire structure was intact. This indicates that the tower failed under rocking motion, with hinges forming below the steel frame. Damage from the formation of hinges was evident at the base of the lower portion of the tower. The joints in the masonry at the location of the hinges were in poor condition, indicating that they had not been recently repointed.

The extents of the large hole through which the tower had fallen, clearly show the effectiveness of the ribs at reinforcing the roof structure. Only the ribs immediately impacted 
by the tower failed. Adjacent ribs confined the collapse to the area of the impact only. It can be observed that this rib pattern increased the depth of the vault, giving it a greater capacity than the Totolapan Monastery, and also introduced more redundancy into the design, allowing part of the vault to remain intact despite the collapse of the tower.

The remaining roof vaults which were not damaged by the tower still exhibited recurring cracking and spalling. The side walls of the nave were subjected to out of plane forces and would have displaced in out of plane bending. The cracking is more significant at the apse which, due to the semi-circular floor plan and large number of exterior buttresses, had created a stiff point resisting the movement of the rest of the roof. The wall on the north side of the nave is stiffened by large buttresses, but the south wall is connected to the two-storey cloister that increases the stiffness of this wall, with additional cross walls/buttresses. The two walls of the nave have different fundamental periods and resonance frequencies, resulting in differential movement. At some time during the earthquake, the tops of the walls moved apart, creating a geometric imbalance and caused cracking in the vaulted roof parallel to the side walls.
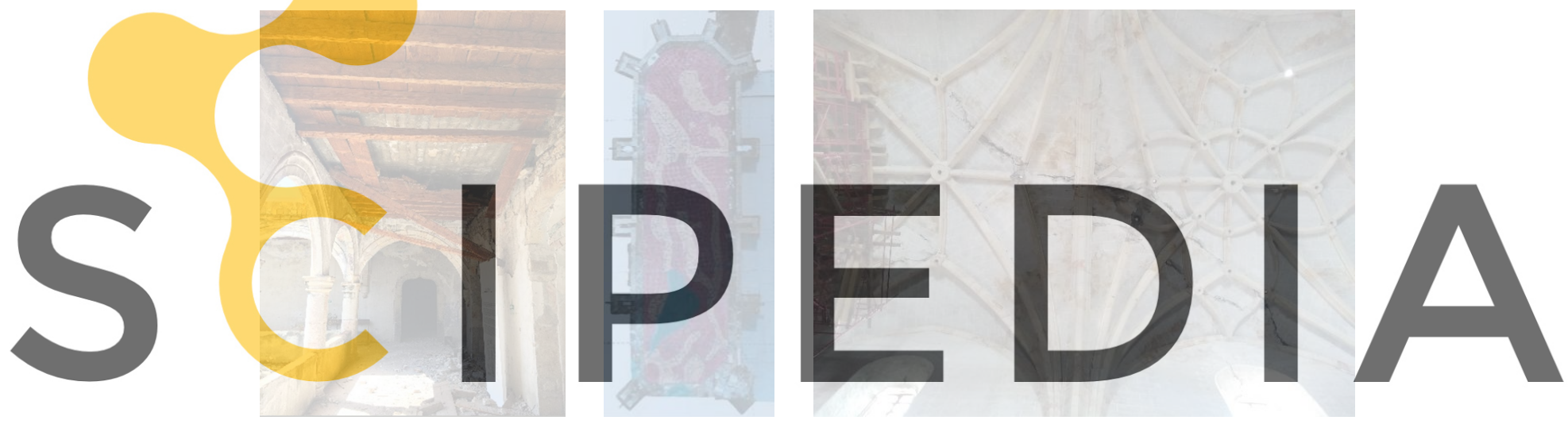
to ribbed vault, May 2019.

The roof of the adjacent convent was originally of heavy timber construction, with plank decking. This type of construction is flexible, and absorbs energy. After the 1999 earthquake the wood was removed and replaced with reinforced concrete slabs. This is an inappropriate intervention since it is now an extremely stiff element which distributes the energy to the adjacent walls. The impact of the added stiffness during the earthquake was immediately apparent. First, where the slab abutted the wall of the church, the slab pounded into the masonry, resulting in localized masonry failure. Second, these slabs have a significant impact on the natural frequency of the adjacent monastery and therefore the south wall of the nave, likely causing greater damage to the roof of the nave. The reinforced concrete slabs remained intact, with no cracking noted. In some areas the large arched openings of the convent were infilled with stone masonry. The infill masonry had separated during the earthquake. This damage is due to a poor construction detail, where the interior wall was constructed after the exterior wall, with no key stones installed across the construction joint.

In areas where the plaster was removed from the walls, it can be seen that the walls are well 
constructed. The masons used large angular stones set in adobe mortar. It is probable that the stones are of variable depth, creating a keying action with the wall core. Very little cracking on the longitudinal walls of the nave was observed even though, on the upper parts of the walls, many voids and weathered mortar joints were noted. The large buttresses supporting these walls were also undamaged. It is likely the better maintenance and construction practices using larger stones and keystones ensured that these walls had adequate seismic resistance, in comparison to the buttresses at Totolapan.

The ribbed vault roof of the Open Chapel appears to have a number of fractures with a similar pattern as the fractures following the 1999 earthquake. There is evidence of previous repairs at these hinges, by filling the cracks with, possibly, cementitious grout. The repair failed during this earthquake, causing the cracks to reopen. This highlights the need to rebuild across cracks with solid material, as simple infilling leaves the previous failure as a weak point, and does not allow the assembly to act as a singular unit.

\section{CONCLUSIONS}

It can be clearly seen from the study of these two historic monasteries, that the ability to perform maintenance is difficult and expensive. Such lack of maintenance directly contributes to failure during seismic events. Huaquechula, the better maintained of the two, sustained less damage than Totolapan which suffered substantial loss to the bell tower, barrel vaults,

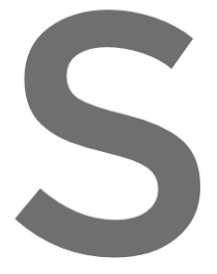
buttresses and upper regions of the walls. Poor bonding of the stome masonry due to deteriorated mortar results in a greater chance of collapse, white well maintaired walls may crack but are
more resilient and less likely to fail. In addition, the act of forming cracks luring a seismic
The study on the performance of adobe structures following the 2017 earthquake supports
the conclusion that structures conserved using compatible materials and respecting the original
construction methodology will perform better than buildings upgraded using contemporary
materials such as Portland mortars. concrete and steel [10].

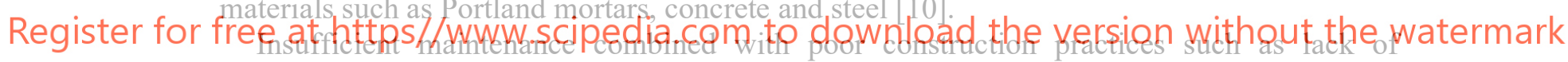

keystones contributed to the observed failures at both monasteries. The introduction of contemporary materials to repair damage resulting from repeated seismic activity over the centuries has compounded the deterioration. In the case of Totolapan, there is extensive use of Portland cements and at Huaquechula the use of steel reinforcement in the bell tower, the addition of concrete slabs at the cloister, along with lack of masonry conservation resulted in collapse of the tower. The addition of inflexible materials provided stiffness to the walls and roofs, resulting in differing return periods for the buttresses on opposite sides of the nave, supplying tension in the roof dome, and the ensuing fracturing of the roof structure.

Evidence has shown that the introduction of non-compatible materials to a historic masonry structure will accelerate decline, primarily by impeding vapour transmission, regardless of the geographical location and climatic conditions. Moisture is a natural component of a masonry wall; the amount will be dependent on how well the masonry is protected. Historically, soft, low strength, flexible lime and clay mortars acted like blotting paper to draw moisture to the surface of the masonry through capillary action and evaporate [15]. This provides resistance to freeze-thaw in colder climates. Natural salts activated by moisture trapped in the masonry can also be detrimental to the masonry components, such is the case with the use of Portland cement 
based mortars, grouts and plasters where the pore size of the cement is too small to permit capillary action and vapour transmission. The outcome results in the confined moisture attacking the existing lime mortar, reducing it to sand and within a relatively short period of time the interface of the contemporary and existing material will debond. This becomes a major component in the extent of masonry failure due to seismic forces. Another factor which leads to deterioration of the masonry is the strength of the contemporary mortar. If the mortar is more than $25 \%$ to $30 \%$ stronger than the surrounding masonry, the integrity of the wall will suffer.

It is a vital part of the Conservation process to replace all deteriorated mortar and fill all voids to consolidate the masonry, so that in the event of an earthquake, the masonry will act as a single unit. Use of soft, flexible mortars will act as "shock absorbers" during a seismic event and improve longevity by allowing vapour transmission to occur. Properly maintained masonry coupled with the use of compatible materials and repair methodologies will ensure acceptable building performance in a seismic event [16].

It is clear that if we are to conserve our heritage fabric for future generations to enjoy and respect, we must reach a gentler understanding of the need to repair like with like and avoid the mistakes of past generations. It will be necessary to perform extensive testing to develop compatibility with existing materials, revive the old construction methodologies and train the tradespeople in the crafts and techniques required to achieve this.

\section{ACKNOWLEDGEMENTS}

Part of this research was supported by the International Research Seed Grant by Carleton University. Our gratitude goes to the different stakeholders from Mexico, including Instituto Nacional de Antropologia e Historia (INAH), Teresita Miravete from INAH Puebla and Fernando Duarte from INAH Morelos. As well as the Grupo Farla for allowing several site visits. Special thanks to Dr. Xavier Cortes Rocha, Ing. Roberto Heatley, Arq. Salvador Avila, Lic. Ricardo Esponda, Arq. Elisa Vera, Mary Cooke, and Jamie Marrs. The images from October 2017 were taken by Ing. Roberto Heatly.

\section{REFERENCES}

[1] Meli, R. La ingenieria civil ante los efectos de los sismos de 2017 en edificios patrimoniales. Sismos y Patrimonio Cultural. Secretaria de la Cultura, Mexico. (2018)

[2] Conventos Moralenses. Lunwerg, S.L. Espana. (2012)

[3] Earliest $16^{\text {th }}$-Century Monasteries on the Slopes of Popocatepetl. UNESCO World Heritage Centre. Available: https://whc.unesco.org/en/list/702

[4] Meli, R. Los Conventos Mexicanos del Siglo XVI. Construccion, Ingenieria Estructural y Conservacion. Instituto de Ingenieria UNAM, Porrua, Mexico (2011).

[5] Grupo Farla. Reporte Templo Ex-Convento de San Guillermo Totolapan, 2do Simposio Internacional entre especialistas de Mexico y Union Europea. (2019)

[6] Gonzalez Leyva, A. Construccion y Destruccion de Conventos del siglo XVI. Cultura FONCA, Mexico (2019).

[7] Hall, M.R., Lindsay, R., and Krayenhoff, M. Modern Earth Buildings - Materials, Engineering, Construction and Applications. Woodhead Publishing, (2012).

[8] Walter, T.L. Espiritu Santo de Zúñiga. A Frontier Mission in South Texas. University of Texas Press, (2007). ProQuest Ebook Central. 
[9] Tolles, E.L., Kimbro, E.E., Webster, F.A., and Ginell, W.S. Seismic Stabilization of Historic Adobe Structures: Final Report of the Getty Seismic Adobe Project, Getty Conservation Institute, Los Angeles: Calif, (2000).

[10] Fernando, L. and Baca, G. Comportamiento sísmico de viviendas tradicionales de adobe, situadas en las faldas del volcán Popocatépetl, México. Gremium (2019). Vol. 6, no. 11.

[11] Heyman, J. The Safety of Masonry Arches. International Journal of Mechanical Science, (1969). Vol 11, pp. 363-385.

[12] Mendoza, T.C. Ex Convento de San Guillermo. Photo - Dec 2016 (Google).

[13] Kalalo, E. Convento de San Martin Caballero. Photo - May 2017 (Google).

[14] Grupo Escoda. Propuesta de Restauracion y Consolidacion Estructural del Templo de San Martin Huaquechula / Levantamiento y Digitalizacion. Mexico. February 2019.

[15] Wiggins, D. Traditional lime mortars and masonry preservation. The Journal of the Building Limes Forum. (2017) Vol 24, Pp. 28-37.

[16] Esponda, M. Ph.D thesis "Assessment of the Reinforced Concrete in the Restoration of Buildings in Mexico \& Spain” Universidad Politécnica de Cataluña, Spain. (2004).

[17] Ledesma Gallegos, L., Gonzalez Leyva, A. Y hasta ahora todo ha sido hacer y deshacer edificios. Mexico, D.F. INAH. (2005) p. 44

[18] Memoria Fonden 2000. Rehabilitacion de inmuebles historicos danados por los sismos de junio y septiembre de 1999. CONACULTA. INAH. Mexico. (2000)

[19] Kubler, G. Arquitectura Mexicana del Siglo XVI. Fondo de Cultura Econ. Mexico (1984)

[20] Perales Piqueres R., Benites de Unanue M. P. Los Conventos del siglo XVI de Puebla y Morelos. UPAEP. (2018)

[21] Kostoglodov, V. and Pacheco, J.F. Cien años de sismicidad en México. UNAM, (1999). 